\title{
Axial Signs and Magnetic Resonance Imaging Correlates in Parkinson's Disease
}

\author{
Hernish J. Acharya, Thomas P. Bouchard, Derek J. Emery, Richard M. Camicioli
}

\begin{abstract}
Background: Age-related brain changes may contribute to axial features in Parkinson's disease (PD). Objectives: To determine if ventricular volume and white matter high signal changes (WMC) are related to motor signs in PD and controls independent of age. Methods: Patients were rated with the Unified Parkinson's Disease Rating Scale (subscore A: tremor, rigidity, bradykinesia, and facial expression; subscore B: speech and axial impairment). Steps and time taken to walk 9.144 meters were measured. Total ventricular volume (TVV) and intracranial volume (ICV) were measured on T1-weighted MRI using manual tracing software. WMC were rated on axial T2-weighted, dual-echo or FLAIR MR images using a visual scale. Results: TVV (cm ${ }^{3}$ ) (PD: $36.48 \pm 15.93$; controls: $32.16 \pm$ 14.20, $\mathrm{p}=0.21$ ) and WMC did not differ between groups (PD: $3.7 \pm 4.2$; controls: $3.2 \pm 3.1$, $\mathrm{p}=0.55$ ). Age correlated positively with ICV-corrected TVV and WMC in PD (cTVV: $r=0.48, p=0.003$; WMC: $r=0.42, p=0.01)$ and controls $(\mathrm{cTVV}: \mathrm{r}=0.31, \mathrm{p}=0.04$; WMC: $r=0.44, p=0.003)$. Subscore B $(r=0.42, p=0.01)$ but not subscore A $(r=0.25, p=0.14)$ correlated with cTVV in PD. Steps and walking time correlated with cTVV and WMC in PD; cadence correlated with cTVV and steps with WMC in controls. Age-adjustment eliminated correlations. Conclusion: Subscore B, but not subscore A correlated positively with ventricular volume in PD, though this association was accounted for by age. Age-related brain change super-imposed on PD may contribute to axial features.
\end{abstract}

RÉSUMÉ: Les signes axiaux et l'imagerie par résonance magnétique sont corrélés dans la maladie de Parkinson. Contexte : Les changements du cerveau qui sont reliés à l'âge peuvent contribuer aux manifestations axiales dans la maladie de Parkinson (MP). Objectifs : Déterminer si le volume ventriculaire et les changements du signal élevé de la substance blanche (CSB) sont reliés aux signes moteurs chez des patients atteints de MP et chez des sujets témoins, sans égard à l'âge. Méthodes : Les patients étaient évalués au moyen de la Unified Parkinson's Disease Rating Scale (sous-score A : tremblement, rigidité, bradycinésie et expression faciale; sous-score B : dysarthrie et manifestations axiales). Les pas et le temps requis pour parcourir 9.144 mètres ont été mesurés. Le volume ventriculaire total (VVT) et le volume intracrânien (VIC) ont été mesurés par IRM pondérée en T1, au moyen d'un logiciel de calque manuel. Les CSB ont été évalués au moyen d'une échelle visuelle sur des images axiales pondérées en T2, double écho ou FLAIR. Résultats : Le VVT (cm3 ) (MP : 36,48 \pm 15,93; témoins : 32,16 \pm 14,20; p = 0,21) et les CSB n'étaient pas différents entre les groupes (MP $: 3,7 \pm 4,2$; témoins : $3,2 \pm 3,1 ; p=0,55)$. L'âge était corrélé au VVT corrigé pour le VIC et les CSB dans la MP $(\mathrm{VVTc}: \mathrm{r}=0,48 ; \mathrm{p}=0,003 ; \mathrm{CSB}: \mathrm{r}$ $=0,42 ; p=0,01)$ et les témoins (VVTc $: r=0,31 ; p=0,04 ; C S B: r=0,44 ; p=0,003)$. Le sous-score $B(r=0,42 ; p=0,01)$ était corrélé au VVTc chez les patients atteints de MP, mais non le sous-score A $(r=0,25 ; \mathrm{p}=0,14)$. Les pas et le temps de marche étaient corrélés au VVT et aux CSB dans la MP; la cadence était corrélée au VVTc et les pas aux CSB chez les témoins. L'ajustement pour l'âge annulait les corrélations. Conclusion : Il y avait une corrélation positive entre le sous-score B et le volume ventriculaire dans la MP, ce qui n'était pas le cas du sous-score A, mais cette association était due à l'âge. Les changements reliés à l'âge surajoutés à la MP peuvent contribuer aux manifestations axiales chez les patients atteints de MP.

Can. J. Neurol. Sci. 2007; 34: 56-61

Parkinson's disease (PD), a common neurodegenerative movement disorder, affects adults of all ages, particularly those over age 65. It is diagnosed based on the motor manifestations of the disease. Over the last 40 years, 1-dopa has emerged as the mainstay of treatment, though not all motor deficits respond equally to dopamine replacement. Some features, including tremor, rigidity, bradykinesia, and masked facial expression respond well to levodopa, while other features including axial motor impairment and speech dysfunction do not respond as well to dopaminergic medications. The former may be due to focal nigral dopaminergic cell loss while the latter may be due to degeneration of non-dopaminergic neural circuitry beyond the midbrain, ${ }^{1}$ which may be age-related..$^{2-4}$

From the Department of Medicine, Division of Neurology (HJA, TPB, RMC), Department of Radiology and Diagnostic Imaging (DJE), University of Alberta, Edmonton, Alberta, Canada.

ReCeived July 10, 2006. ACCEPTED IN FINAL FORM November 6, 2006. Reprint requests to: Richard Camicioli, E223, Glenrose Rehabilitation Hospital, 10230 111th Avenue, Edmonton, Alberta, T5G 0B7, Canada. 
Ventricular enlargement reflects central brain atrophy, which occurs with aging and white matter disease, and is associated with gait impairment ${ }^{5,6}$ and parkinsonian signs. ${ }^{7}$ The size of the ventricles has been evaluated in PD with computed tomography $(\mathrm{CT})^{8-10}$ and magnetic resonance imaging (MRI). ${ }^{11-13}$ Previous studies considering the ventricles in PD using MRI either used linear techniques, ${ }^{11}$ lacked control groups, ${ }^{11,13}$ or did not calculate the absolute ventricular volumes. ${ }^{12}$ In addition, studies of ventricular volumes in PD have not examined white matter changes, which are also associated with aging. In studies that have examined white matter changes specifically in PD, they have been associated with rapid progression ${ }^{14}$ and dementia. ${ }^{15}$

Studies assessing the relationship between PD symptomatology and aging have grouped symptoms and signs from the Unified Parkinson's Disease Rating Scale (UPDRS) into tremordominant (TD) and postural instability-gait difficulty-dominant (PIGD) PD. ${ }^{16}$ It has been shown that the PIGD group has a more rapid rate of symptom progression ${ }^{17}$ and cognitive decline ${ }^{18}$ than the TD group. An analogous way of grouping UPDRS signs is into subscore A (which largely correlates with dopamineresponsive features and manifests as non-axial impairment) and subscore B (which largely correlates to dopamine nonresponsive dysfunction and manifests as axial impairment). ${ }^{2}$ Levy et $\mathrm{al}^{2,19}$ found that age contributes to disease severity, particularly axial impairment, reflected in subscore B.

Given the strong relationship between age, ventricular volume and white matter disease, we compared ventricular volumes and white matter high signal changes between PD patients and age-matched controls to determine if PD was associated with increased ventricular size or severity of white matter hyperintense lesions. In addition, we determined the relationship between ventricular size, white matter disease, and motor manifestations of PD. We also examined the relationship between age and these MRI measures and quantified gait in PD and controls. Lastly, we adjusted for age to determine the extent to which age itself drove any observed relationships. We hypothesized that in PD ventricular volumes would correlate with subscore $\mathrm{B}$, reflecting axial impairment and that this relationship would be partially accounted for by age and white matter disease. We anticipated that gait measures would show parallel changes.

\section{MeTHODS \\ Participants}

Thirty-six patients with PD were recruited from the Movement Disorders Clinic at the University of Alberta. Fortythree control subjects were recruited from the community by advertisement or word of mouth. Patients and controls provided informed consent for a University of Alberta Health Ethics Review Board approved protocol. Inclusion criteria for the PD group included: ability to speak English, UK PD Society Brain Bank Clinical Diagnosis Criteria for parkinsonism (at least 2 of tremor, rigidity, bradykinesia), ${ }^{20}$ Hoehn and Yahr Rating Scale $(\mathrm{HYS})^{21}$ score of 1 to 4 when 'off,' Clinical Dementia Rating Scale (CDR) ${ }^{22}$ score of $<1.0$ (if 0.5 , no functional impairment on the basis of cognitive function), Mini-Mental Status Exam $(\mathrm{MMSE})^{23}$ score of $>23$, independent ambulation with or without walking aids, ability and willingness to comply with assessments, use of stable doses of medications for at least one month, a reliable informant, and informed consent. In order to maximize the likelihood that a patient had idiopathic PD, all patients had an established diagnosis of PD and the diagnosis was reviewed by a movement disorder specialist (RC). No patient had cerebellar signs, early autonomic dysfunction or supranuclear gaze palsy. Exclusion criteria included: unstable medical conditions or conditions that affect cognition (e.g., recent myocardial infarction, active angina, congestive heart failure), medications with direct cognitive effects, severe depression or psychosis requiring treatment changes, dementia by DSM-IV criteria, ${ }^{24}$ use of cognitive enhancing drugs within one month, central nervous system disease with cognitive sequelae, active cancer, alcoholism or drug abuse, or contraindications to MRI. Criteria for the control group were identical to the PD group, except that they did not have PD. People with MRI scans available for both volumetric and white matter rating were included.

\section{Clinical Measures}

Overall disease severity was staged using the HYS. Symptoms and signs of PD were assessed using the UPDRS. ${ }^{25}$ Patients rated "on" and "off" symptoms (UPDRS2), but were examined when in the "on" state 1.0 - 3.0 hours after taking their usual medications. Total UPDRS (sum of UPDRS 1, 2, and 3) and the motor subscale of the UPDRS (UPDRS3) were rated by a neurologist specialized in movement disorders (RC). UPDRS3 sub-scores for tremor, rigidity, bradykinesia, and facial expression were summed to yield subscore A (maximum score: 88) while sub-scores for speech and axial impairment were summed to yield subscore B (maximum score: 20) as previously published. ${ }^{2}$ The gait task has been described elsewhere. ${ }^{6}$ Briefly, subjects walked $9.144 \mathrm{~m}$, including a turn at the mid-point, at a self-selected pace. The time and number of steps were recorded. Number of steps, time, and cadence are means from two trials.

\section{Cognitive Measures}

Cognitive function was assessed by the Dementia Rating Scale $^{26}$ and the MMSE. The CDR rating was based on subject/caregiver interviews.

\section{Imaging}

The MRI was performed on a Siemens Sonata 1.5T system with subjects in the "on" state. A coronal 3-D magnetization prepared rapid acquisition gradient echo sequence $(\mathrm{TR}=$ $1800 \mathrm{~ms}, \mathrm{TE}=3.82 \mathrm{~ms}$, inversion time $(\mathrm{TI})=1100 \mathrm{~ms}, 1$ average, flip angle $=15$ degrees, FOV $=256 \mathrm{~mm}$, resolution $=256 \mathrm{X} 256$, 128 slices, $1.5 \mathrm{~mm}$ slice thickness) aligned to the anterior commissure-posterior commissure line was used for manual tracing. White matter changes were rated either with an axial dual-echo sequence $(\mathrm{TR}=6330 \mathrm{~ms}, \mathrm{TE}=24 / 83 \mathrm{~ms}, 1$ average, FOV $=240 \mathrm{~mm}$, 50 slices, $3 \mathrm{~mm}$ ), or with the combination of an axial T2-weighted sequence (TR=7000ms, TE $=99 \mathrm{~ms}, 2$ averages, FOV $=220 \mathrm{~mm}, 25$ slices, $5 \mathrm{~mm}$ slice thickness) and an axial FLAIR sequence $(\mathrm{TR}=8000 \mathrm{~ms}, \mathrm{TE}=94 \mathrm{~ms}, 1$ average, $\mathrm{FOV}=220 \mathrm{~mm}$, 25 slices, $5 \mathrm{~mm}$ slice thickness). 


\section{Volumetric Measurement}

Intracranial, and lateral and third ventricular volumes were measured using the software program DISPLAY (available online at http://www.bic.mni.mcgill.ca/software/distribution) while obeying strict previously published anatomic boundaries. $^{27-29}$ Lateral and third ventricular volumes were summed to yield total ventricular volume (TVV) which was corrected for intracranial volume (ICV) (cTVV). ${ }^{30}$

\section{White Matter Disease Rating}

White matter changes were rated using a published rating scale amenable to use with various imaging modalities. ${ }^{31}$ In brief, lesions were rated in the right and left frontal, parietooccipital, temporal and infra-tentorial brain areas on a four level scale with a score of 0 representing no white matter changes or well-defined caps or bands, 1 indicating focal lesions, 2 indicating beginning confluent lesions and 3 indicating confluent lesions. The right and left basal ganglia were also rated, with a score of 0 representing no lesion, 1 indicating one focal lesion (>5 mm), 2 indicating more than one focal lesion, and 3 indicating confluent involvement. The total white matter score for all areas, right and left, was used in analyses. The scores could range from 0 to a maximum of 30 . One rater (DJE, a board certified neuroradiologist) rated all the scans from the current study in order to avoid potential systematic biases in rating.

\section{Data Analysis}

Intra and inter-rater reliability for volume measurements were determined using a two-way mixed effect model (absolute agreement) intra-class correlation coefficient (ICC) from five randomly selected scans traced by two raters (HA and TB). The same statistics were used to assess reliability for rating white matter disease severity between two raters (RC and DJE) independently on 36 scans. Analysis of variance (ANOVA) was performed to assess between group differences. Correlations were calculated using bivariate and multivariable linear regression models. Age, cTVV and white matter were used in correlation analyses and colinearity was examined. A "UPDRS2 off - on" score was calculated as follows: (UPDRS2 off UPDRS2 on)/UPDRS2 off. Comparisons between regression lines were performed by using Student's t-test to compare the slope and y-intercept of the lines. ${ }^{32}$ All statistical analyses were carried out with SPSS 13.0 and Microsoft Excel. The threshold for statistical significance was set at $\mathrm{p}<0.05$.

\section{RESULTS}

\section{Demographics}

The groups were well-matched for age, education, height and sex (Table 1).

\section{Clinical Characteristics}

Groups did not differ on the MMSE (range for PD $=25-30$, range for controls $=24-30$ ) nor the Dementia Rating Scale (range for $\mathrm{PD}=129-144$, range for controls = 130-144). Mean severity of disease assessed by HYS was mild to moderate on average. No subject was demented. Differences in cadence and steps were not statistically significant, though PD subjects took significantly more time to complete the gait task (Table 1).
Table 1: Demographic and clinical characteristics (means \pm standard deviations are reported)

\begin{tabular}{|c|c|c|c|c|}
\hline & & $\mathrm{PD}(\mathrm{n}=36)$ & Control $(n=43)$ & p-value \\
\hline \multirow{4}{*}{ 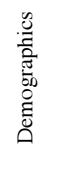 } & Age (y) & $68.75 \pm 6.72$ & $70.35 \pm 5.78$ & 0.26 \\
\hline & Education (y) & $14.03^{\circ} \pm 3.88$ & $14.74 \pm 3.35$ & 0.38 \\
\hline & Height (m) & $1.70 \pm 0.11$ & $1.71 \pm 0.10$ & 0.82 \\
\hline & Sex (M:F) & $21: 15$ & $21: 22$ & 0.71 \\
\hline \multirow{7}{*}{ 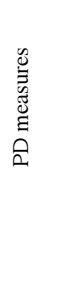 } & UPDRS 1 & $1.34 \pm 1.24$ & $0.35 \pm 0.57$ & 0.000 \\
\hline & UPRDS 2 & $8.99 \pm 5.38$ & $0.72 \pm 1.53$ & 0.000 \\
\hline & UPDRS 3 & $16.14 \pm 9.01$ & $2.07 \pm 3.15$ & 0.000 \\
\hline & Total UPDRS & $26.54 \pm 13.80$ & $3.12 \pm 4.24$ & 0.000 \\
\hline & Subscore A & $13.39 \pm 7.14$ & $1.72 \pm 2.30$ & 0.000 \\
\hline & Subscore B & $2.75 \pm 2.61$ & $0.42 \pm 1.31$ & 0.000 \\
\hline & HYS & $2.15 \pm 0.58$ & $0.00 \pm 0.00$ & 0.000 \\
\hline \multirow{3}{*}{ 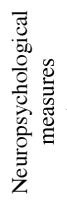 } & MMSE & $28.44 \pm 1.58$ & $28.37 \pm 1.72$ & 0.85 \\
\hline & Dementia Rating Scale & $138.25 \pm 3.93$ & $138.37 \pm 3.57$ & 0.91 \\
\hline & CDR & $0.03 \pm 0.12$ & $0.01 \pm 0.08$ & 0.46 \\
\hline \multirow{3}{*}{ 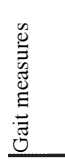 } & Steps (number) & $18.78 \pm 3.23$ & $17.64 \pm 2.50$ & 0.08 \\
\hline & Time (s) & $14.08 \pm 3.15$ & $11.70 \pm 2.79$ & 0.001 \\
\hline & Cadence (steps/time) & $1.65 \pm 0.18$ & $1.67 \pm 0.15$ & 0.64 \\
\hline
\end{tabular}

PD, Parkinson's disease; UPDRS, Unified Parkinson's Disease Rating Scale; HYS, Hoehn and Yahr Scale; MMSE, Mini-Mental Status Exam; CDR, Clinical Dementia Rating Scale

\section{Volumetric and White Matter Measures}

The ICCs were excellent for ICV (1.00), left lateral (0.99), right lateral (0.99), and TVV (0.99), but lower for the third ventricular volume (0.62). TVV was normalized for ICV to eliminate differences in ventricular volume due to head size (cTVV). Table 2 shows raw ICV and ventricular volumes with pvalues for both raw and corrected volumes. Volumes did not differ between groups.

The ICC for white matter rating was very good (0.80). Total white matter severity scores (controls: $3.2 \pm 3.1$; PD patients: 3.7

\section{Table 2: Volumetric measures (means \pm standard deviations are reported)}

\begin{tabular}{lccc}
\hline & PD $(n=36)$ & Control $(\mathrm{n}=43)$ & p-value raw (corrected) \\
\hline ICV cm $^{3}$ & $1523.51 \pm 154.86$ & $1509.75 \pm 161.83$ & 0.70 \\
TVV cm $^{3}$ & $36.48 \pm 15.93$ & $32.16 \pm 14.20$ & $0.21(0.15)$ \\
LLVV cm & $17.99 \pm 8.93$ & $15.43 \pm 7.35$ & $0.17(0.12)$ \\
RLVV cm & $15.76 \pm 6.88$ & $14.07 \pm 6.85$ & $0.28(0.20)$ \\
3 rdVV cm $^{3}$ & $2.73 \pm 0.89$ & $2.67 \pm 0.86$ & $0.74(0.66)$ \\
\hline
\end{tabular}

$\mathrm{ICV}$, intracranial volume; TVV, total ventricular volume; LLVV, left lateral ventricular volume; RLVV, right lateral ventricular volume; 3rdVV, third ventricular volume. p-values are shown for raw and corrected ventricular volumes. 
$\pm 4.2, \mathrm{p}=0.55)$ did not differ between groups. Moreover, the proportion of subjects with white matter changes was not different between groups $(\mathrm{p}=0.47)$ : $75 \%$ of PD subjects and $67 \%$ of controls had white matter changes. White matter severity correlated with cTVV $(\mathrm{r}=0.39, \mathrm{p}=0.02)$ in patients, but not controls $(r=0.10, p=0.54)$.

\section{Correlations}

Effect of age on ventricular volume and white matter high signal in PD and controls.

Age correlated positively with cTVV and white matter disease severity in PD (cTVV r $=0.48, p=0.003$; white matter $r$ $=0.42, \mathrm{p}=0.01$ ) and controls (cTVV r $=0.31, \mathrm{p}=0.04$; white matter $\mathrm{r}=0.44, \mathrm{p}=0.003$ ). The best fit lines produced by linear regression for cTVV were not different between groups (Figure). Age, ventricular volume and white matter disease were correlated in the overall group. Age correlated most strongly with cTVV $(\mathrm{r}=0.37, \mathrm{p}=0.001)$ and white matter rating $(\mathrm{r}=$ $0.41, \mathrm{p}<0.001)$, with a weaker correlation between cTVV and white matter rating $(\mathrm{r}=0.28, \mathrm{p}=0.01)$.

\section{Disease and treatment-related correlations}

The total UPDRS and UPDRS3 scores were not significantly associated with disease duration $(\mathrm{r}=0.05, \mathrm{p}=0.80 ; \mathrm{r}=-0.01, \mathrm{p}$ $=0.94)$ or dopaminergic medication dosages $(r=-0.22, p=0.26$;

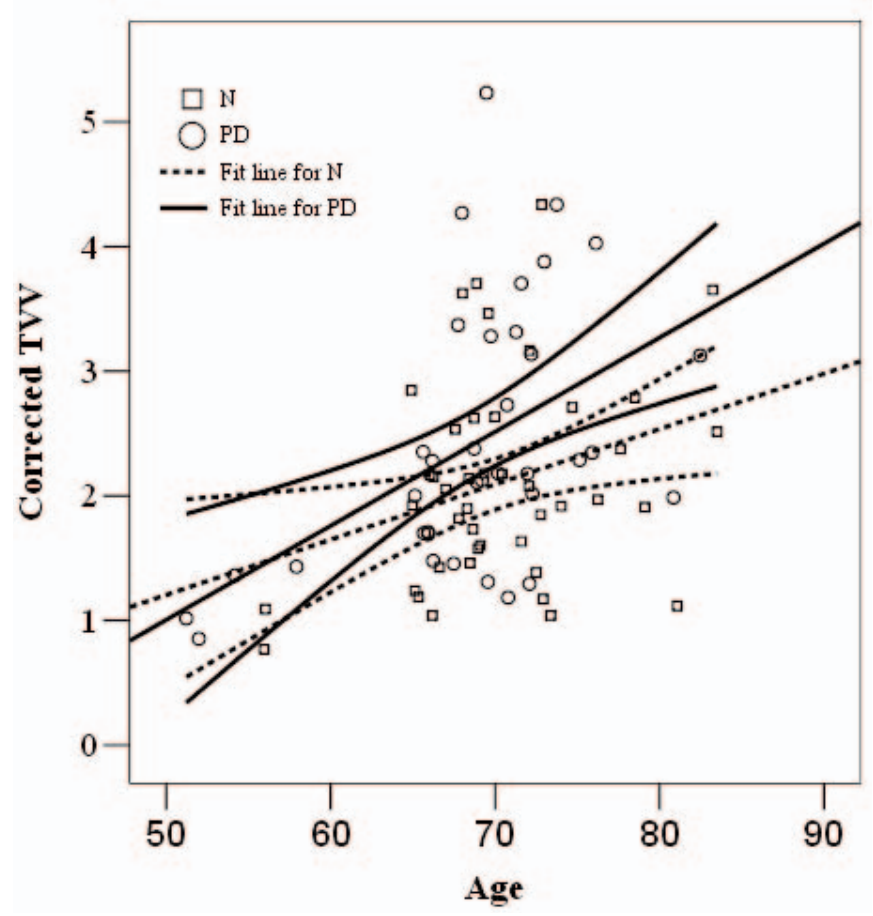

Figure: Corrected total ventricular volumes increases with age in PD and controls. Linear regression lines (fit lines) and confidence intervals are shown. There were no differences between the regression lines (see text). PD, Parkinson's disease; $N$, controls. $\mathrm{r}=-0.15, \mathrm{p}=0.45)$. Disease duration was correlated with subscore B $(\mathrm{r}=0.37, \mathrm{p}=0.03)$, but not with subscore A $(\mathrm{r}=$ $0.15, \mathrm{p}=0.38$ ).

\section{Subscores A and B; Correlations in PD}

The UPDRS2 off - on score correlated negatively with subscore A $(r=-0.46, p=0.006)$, but not with subscore B $(r=-$ $0.26, p=0.13)$, cTVV $(r=-0.30, p=0.08)$, nor white matter severity $(\mathrm{r}=-0.22, \mathrm{p}=0.21)$.

Age and cTVV both correlated positively with total UPDRS, UPDRS3 and subscore B, but not with subscore A. White matter rating did not correlate with total UPDRS, UPDRS3 or subscore A, but showed a non-significant trend with subscore B $(r=0.29$, $\mathrm{p}=0.09$ ). A multivariable linear regression with age, height and education as covariates was significant $(r=0.71, p<0.001)$. When cTVV and white matter severity were added as independent variables, age remained significant, while neither cTTV nor white matter severity added significantly to the model $(\mathrm{r}=0.72, \mathrm{p}<0.001)$.

\section{Correlations with Gait and Balance}

In PD, the cTVV and white matter rating correlated positively with the number of steps and walking time to complete the gait task, but not with cadence. Age correlated positively with steps and walking time, and negatively to average cadence (see Table 3).

In controls, steps and walking time did not correlate significantly with cTVV. Cadence correlated negatively with $\operatorname{cTVV}(\mathrm{r}=-0.32, \mathrm{p}=0.04)$. Walking time and cadence did not correlate with white matter change. Steps correlated significantly with white matter change $(\mathrm{r}=0.36, \mathrm{p}=0.02)$. Age was correlated to steps $(r=0.35, p=0.02)$, walking time $(r=0.34, p=0.03)$ and cadence $(r=-0.35, p=0.02)$.

Correlations were no longer significant after adjusting for age, height and education (data not shown).

\section{DISCUSSION}

In this study, we reliably measured ventricular volumes and white matter changes in PD and controls and examined their relationship to age and clinical motor measures. There were no volumetric or white matter differences between groups, consistent with most other studies. ${ }^{15,33,34}$ Our results suggest that there was no differential ventricular enlargement or increased prevalence of white matter high signal lesions due to the presence of PD in contrast with some studies. , $^{8,10,14,35,36}$

Ventricular enlargement is known to occur in healthy aging. ${ }^{37}$ We found positive correlations between age and ventricular volumes in both groups, consistent with previous studies. ${ }^{7,36}$ There was no difference in the regression lines of age versus cTVV, ${ }^{32}$ indicating age-effects in both groups. In a longitudinal study, $\mathrm{Hu}$ et $\mathrm{al}^{12}$ found no increase in ventricular volume in controls $(n=12$, mean age $=72)$ but a mean increase of $1.23 \mathrm{ml}^{3}$ per year in PD $(n=8$, mean age $=64)$ over two years using an image subtraction method. Further longitudinal study in a larger sample is needed to analyze rates of change. By excluding subjects with dementia we would eliminate subjects with advanced PD, who might show more ventricular dilatation.

Ventricular volumes in PD positively correlated with subscore B, which has been previously described to reflect 
Table 3: Correlations between ventricular volumes, white matter high signal severity and motor measures in PD

\begin{tabular}{lcccc|ccc}
\hline \multicolumn{4}{c|}{ UPDRS parameters, $\mathrm{r}(\mathrm{p}$-value) } & \multicolumn{3}{|c}{ Gait parameters, $\mathrm{r}(\mathrm{p}$-value) } \\
\hline \multirow{4}{*}{ Total } & UPDRS3 & $\mathrm{A}$ & $\mathrm{B}$ & \multicolumn{2}{c}{$\begin{array}{c}\text { Number } \\
\text { of steps }\end{array}$} & Time & Cadence \\
CTVV & UPDRS & & & & & \\
& 0.37 & 0.32 & 0.25 & 0.42 & 0.40 & 0.42 & -0.15 \\
WMC & $0.03)$ & $(0.06)$ & $(0.14)$ & $(0.01)$ & $(0.02)$ & $(0.01)$ & $(0.38)$ \\
& $(0.18)$ & 0.09 & 0.01 & 0.29 & 0.41 & 0.52 & 0.17 \\
Age & 0.40 & $0.60)$ & $(0.96)$ & $(0.09)$ & $(0.01)$ & $(0.001)$ & $(0.31)$ \\
& $(0.02)$ & $(0.02)$ & $(0.10)$ & $(0.000)$ & $(0.01)$ & $(0.000)$ & $(0.005)$ \\
\hline
\end{tabular}

A, subscore A ; B, subscore B; r, correlation coefficient; cTVV, corrected total ventricular volume; UPDRS, Unified Parkinson's Disease Rating Scale ; WMC, white matter high signal changes

predominantly axial impairment and non-dopaminergic dysfunction, ${ }^{2}$ but not with subscore A which has been previously shown to reflect predominantly non-axial impairment and dopaminergic dysfunction. ${ }^{2}$ The literature so far is contradictory on this point. Schneider et al, ${ }^{7}$ using linear methods, noted that worse cerebral atrophy predicted a poorer response to L-Dopa, while Alegret et $\mathrm{al}^{13}$ found no relationship between central atrophy and motor signs $(\mathrm{N}=14$, mean age $=60$ years $)$. While we considered the subscores separately, Alegret et al examined all UPDRS measures together, and examined relatively few subjects, which may partially account for the discrepancies. Additionally, we examined patients in the "on" state, which may have limited our ability to reliably assess the non-axial features. The UPDRS2 off - on score provides an estimate of dopamine responsivity by history. The correlation of this score with subscore A, but not with subscore B nor cTVV suggests that the subscores are valid. While white matter changes were correlated with age and cTVV, they were not clearly associated with UPDRS derived measures. Given that there were significant inter-correlations between age, ventricular volumes and white matter high signal changes, our ability to separate the relative effects of age from MRI measures in PD was obscured. Nevertheless, the data support an important contribution of age to axial motor measures in PD.

We additionally evaluated simple clinical gait parameters. ${ }^{6}$ Our findings that PD subjects had similar cadence to controls is consistent with the literature in patients with mild to moderate PD (HYS range 1.0 - 3.0). ${ }^{38}$ In PD, cTVV and white matter rating both correlated with steps and time, but not cadence, while in controls cTVV correlated with cadence, white matter rating with steps, but neither MRI measure correlated with time. Age generally correlated with worse gait measures in PD and controls and adjustment for age eliminated all correlations.

Previous studies that have examined white matter changes in PD have suggested an association with poor dopamine response, ${ }^{39}$ rapid progression, ${ }^{14}$ and cognitive impairment. ${ }^{15}$ Some studies have suggested an increased prevalence of vascular pathology in $\mathrm{PD},{ }^{40}$ including periventricular change. ${ }^{14}$ This may have been missed in our sample given a modest sample size and the fact that we did not separate periventricular from deep white matter change. Regardless, our data suggest a significant age effect that contributes to PD reflected, in part, by ventricular dilatation and white matter change. Of interest, a recent study suggested that levodopa refractory patients with parkinsonism and white matter changes do not improve as much from rehabilitation as those with parkinsonism without white matter changes. ${ }^{41}$

It is established that PD pathology extends beyond the substantia nigra and that non-dopaminergic systems are affected. ${ }^{1,3}$ These may be related to subscores A and B, respectively. ${ }^{2}$ Dissociation between dopamine responsive and dopamine non-responsive features is a longstanding idea ${ }^{3,42}$ and motivated us to examine the relationship of ventricular volume and white matter changes with these groups separately via subscores A and B. The correlation between subscore B and ventricular volumes in our sample was accounted for by age, consistent with clinical studies that show an age effect on severity of parkinsonism. ${ }^{5,43}$ Subscore A, conversely, was not related to ventricular volume, consistent with the notion that dopaminergic lesions characteristic of PD may be responsible for those signs.

These results are in keeping with (and provide imaging correlates for) the hypothesis laid out by Levy et $\mathrm{al}^{2}$ that age is a major contributor to subscore B. Our findings suggest a role for age-related ventricular enlargement and possibly white matter changes in the symptomatology of PD. The mechanism by which aging and its imaging correlates affect motor signs is unclear. Longitudinal follow-up is necessary to determine if imaging changes would predict a more rapid rate of disease progression and/or cognitive decline, as has been shown for the PIGD subtype of PD. ${ }^{17,18}$

We studied a group of PD and well-matched controls using highly reliable MRI techniques. Our volumetric approach avoided the problems of the previous literature which used linear methods to estimate ventricular sizes. Parkinsonism was rated using a standard clinical scale (UPDRS) to quantify the symptoms of PD which allows ease of interpretation of the severity of symptoms in our cohort. While we grouped signs as subscore $\mathrm{A}$ and $\mathrm{B}$, we did not directly measure dopaminergic response. Like the majority of studies in the literature, our study was cross-sectional. Moreover, as in most case-control designs, sampling bias might lead to selection of healthier subjects in both the patient and in the control groups. Lastly, the age-range of our cohort was relatively narrow compared to some studies. Collectively, these factors may have prevented us from finding a stronger correlation between age and ventricular volume or white matter disease.

In conclusion, there was no difference in ventricular volumes and severity of white matter changes between PD and controls. Age-associated imaging changes were associated with axial motor features in PD. Longitudinal follow-up and larger samples will be required to separate age-effects from age-associated ventricular change and white matter disease.

\section{ACKNOWLEDGEMENTS}

We acknowledge funding through an operating grant from Canadian Institutes for Health Research (RC) and a pilot grant from the University of Alberta Hospital Foundation. HA was supported by an Alberta Heritage Foundation for Medical 
Research summer scholarship. We thank Sheri Foster and Tracy Greene for assistance with assessment of participants and Pam King and Germaine McInnes for assistance with recruitment of subjects from the Movement Disorder Clinic at the University of Alberta. The University of Alberta for In Vivo NMR Center is funded through operating grants from CIHR.

\section{REFERENCES}

1. Braak H, Braak E. Pathoanatomy of Parkinson's disease. J Neurol. 2000; 247 Suppl 2: II3-10.

2. Levy G, Louis ED, Cote L, Perez M, Mejia-Santana H, Andrews H, et al. Contribution of aging to the severity of different motor signs in Parkinson disease. Arch Neurol. 2005; 62: 467-72.

3. Bonnet AM, Loria Y, Saint-Hilaire MH, Lhermitte F, Agid Y. Does long-term aggravation of Parkinson's disease result from nondopaminergic lesions? Neurology. 1987; 37: 1539-42.

4. Pillon B, Dubois B, Cusimano G, Bonnet AM, Lhermitte F, Agid Y. Does cognitive impairment in Parkinson's disease result from non-dopaminergic lesions? J Neurol Neurosurg Psychiatry. 1989; 52: 201-6.

5. Blin J, Dubois B, Bonnet AM, Vidailhet M, Brandabur M, Agid Y. Does aging aggravate parkinsonian disability? J Neurol Neurosurg Psychiatry. 1991; 54: 780-2.

6. Camicioli R, Moore MM, Sexton G, Howieson DB, Kaye JA. Agerelated brain changes associated with motor function in healthy older people. J Am Geriatr Soc. 1999; 47: 330-4.

7. Schneider E, Becker H, Fischer PA, Grau H, Jacobi P, Brinkmann R. The course of brain atrophy in Parkinson's disease. Arch Psychiatr Nervenkr.1979; 227: 89-95.

8. Kitani M, Kobayashi S, Yamaguchi S. Computerized tomography with longitudinal follow-up of brain atrophy in patients with Parkinson's disease. Gerontology. 1990; 36: 361-8.

9. Starkstein SE, Leiguarda R. Neuropsychological correlates of brain atrophy in Parkinson's disease: a CT-scan study. Mov Disord. 1993; 8: 51-5.

10. Steiner I, Gomori JM, Melamed E. Features of brain atrophy in Parkinson's disease. A CT scan study. Neuroradiology. 1985; 27 : $158-60$.

11. Durif F, Pollak P, Hommel M, Ardouin C, Le Bas JF, Crouzet G, et al. Relationship between levodopa-independent symptoms and central atrophy evaluated by magnetic resonance imaging in Parkinson's disease. Eur Neurol. 1992; 32: 32-6.

12. Hu MT, White SJ, Chaudhuri KR, Morris RG, Bydder GM, Brooks DJ. Correlating rates of cerebral atrophy in Parkinson's disease with measures of cognitive decline. J Neural Transm. 2001; 108: 571-80.

13. Alegret M, Junque C, Pueyo R, Valldeoriola F, Vendrell P, Tolosa E, et al. MRI atrophy parameters related to cognitive and motor impairment in Parkinson's disease. Neurologia. 2001; 16: 63-9.

14. Piccini P, Pavese N, Canapicchi R, Paoli C, Del Dotto P, Puglioli M, et al. White matter hyperintensities in Parkinson's disease. Clinical correlations. Arch Neurol. 1995; 52: 191-4.

15. Beyer MK, Aarsland D, Greve OJ, Larsen JP. Visual rating of white matter hyperintensities in Parkinson's disease. Mov Disord. 2006; 21: 223-9.

16. Jankovic J, McDermott M, Carter J, Gauthier S, Goetz C, Golbe L, et al. Variable expression of Parkinson's disease: a base-line analysis of the DATATOP cohort. The Parkinson Study Group. Neurology. 1990; 40: 1529-34.

17. Jankovic J, Kapadia AS. Functional decline in Parkinson disease. Arch Neurol. 2001; 58: 1611-15.

18. Burn DJ, Rowan EN, Allan LM, Molloy S, O'Brien J T, McKeith IG. Motor subtype and cognitive decline in Parkinson's disease, Parkinson's disease with dementia, and dementia with Lewy bodies. J Neurol Neurosurg Psychiatry. 2006; 77: 585-9.

19. Levy G, Tang MX, Cote LJ, Louis ED, Alfaro B, Mejia H, et al. Motor impairment in PD: relationship to incident dementia and age. Neurology. 2000; 55: 539-44.

20. Litvan I, Bhatia KP, Burn DJ, Goetz CG, Lang AE, McKeith I, et al. Movement Disorders Society Scientific Issues Committee report: SIC Task Force appraisal of clinical diagnostic criteria for Parkinsonian disorders. Mov Disord. 2003; 18: 467-86.
21. Hoehn MM, Yahr MD. Parkinsonism: onset, progression, and mortality. 1967. Neurology. 2001; 57: S11-26.

22. Morris JC. The Clinical Dementia Rating (CDR): current version and scoring rules. Neurology. 1993; 43: 2412-14.

23. Folstein MF, Folstein SE, McHugh PR. "Mini-mental state". A practical method for grading the cognitive state of patients for the clinician. J Psychiatr Res. 1975; 12: 189-98.

24. American Psychiatric Association. Diagnostic and Statistical Manual of Mental Disorders, Text Revision. Washington, D.C.: American Psychiatric Association, 2000.

25. Gancher ST. Scales for the assessment of movement disorders. Handbook of neurologic rating scales 1997:81-106.

26. Brown GG, Rahill AA, Gorell JM, McDonald C, Brown SJ, Sillanpaa M, et al. Validity of the Dementia Rating Scale in assessing cognitive function in Parkinson's disease. J Geriatr Psychiatry Neurol. 1999; 12: 180-8.

27. Eritaia J, Wood SJ, Stuart GW, Bridle N, Dudgeon P, Maruff P, et al. An optimized method for estimating intracranial volume from magnetic resonance images. Magn Reson Med. 2000; 44: 973-7.

28. Buchsbaum MS, Yang S, Hazlett E, Siegel BV, Jr., Germans M, Haznedar M, et al. Ventricular volume and asymmetry in schizotypal personality disorder and schizophrenia assessed with magnetic resonance imaging. Schizophr Res. 1997; 27: 45-53.

29. Brambilla P, Harenski K, Nicoletti M, Mallinger AG, Frank E, Kupfer DJ, et al. MRI study of posterior fossa structures and brain ventricles in bipolar patients. J Psychiatr Res. 2001; 35: 313-22.

30. Whitwell JL, Crum WR, Watt HC, Fox NC. Normalization of cerebral volumes by use of intracranial volume: implications for longitudinal quantitative MR imaging. AJNR Am J Neuroradiol. 2001; 22: 1483-9.

31. Wahlund LO, Barkhof F, Fazekas F, Bronge L, Augustin M, Sjogren $\mathrm{M}$, et al. A new rating scale for age-related white matter changes applicable to MRI and CT. Stroke. 2001; 32: 1318-22.

32. Zar J. Comparing simple linear regression equations. In: Ryu $\mathrm{T}$, editor. Biostatistical analysis. Upper Saddle River: Prentice-Hall; 1999. p.360-8.

33. Camicioli R, Moore MM, Kinney A, Corbridge E, Glassberg K, Kaye JA. Parkinson's disease is associated with hippocampal atrophy. Mov Disord. 2003; 18: 784-90.

34. Camicioli RM, Korzan JR, Foster SL, Fisher NJ, Emery DJ, Bastos $\mathrm{AC}$, et al. Posterior cingulate metabolic changes occur in Parkinson's disease patients without dementia. Neurosci Lett. 2004; 354: 177-80.

35. Schneider E, Fischer PA, Jacobi P, Becker H, Beyer M. Cerebral atrophy and long-term response to levodopa in Parkinson's disease. J Neurol. 1979; 222: 37-43.

36. Becker H, Schneider E, Hacker H, Fischer PA. Cerebral atrophy in Parkinson's disease--represented in CT. Arch Psychiatr Nervenkr. 1979; 227: 81-8.

37. Drayer BP. Imaging of the aging brain. Part I. Normal findings. Radiology. 1988; 166: 785-96.

38. Lewis GN, Byblow WD, Walt SE. Stride length regulation in Parkinson's disease: the use of extrinsic, visual cues. Brain. 2000; 123 (Pt 10): 2077-90.

39. Sohn YH, Kim JS. The influence of white matter hyperintensities on the clinical features of Parkinson's disease. Yonsei Med J. 1998; 39: 50-5.

40. Jellinger KA. Prevalence of cerebrovascular lesions in Parkinson's disease. A postmortem study. Acta Neuropathol (Berl). 2003; 105: 415-19.

41. Guerini F, Frisoni GB, Bellwald C, Rossi R, Bellelli G, Trabucchi M. Subcortical vascular lesions predict functional recovery after rehabilitation in patients with L-dopa refractory parkinsonism. $\mathrm{J}$ Am Geriatr Soc. 2004; 52: 252-6.

42. Lang AE, Obeso JA. Challenges in Parkinson's disease: restoration of the nigrostriatal dopamine system is not enough. The Lancet Neurology. 2004; 3: 309.

43. Koller W, O'Hara R, Weiner W, Lang A, Nutt J, Agid Y, et al. Relationship of aging to Parkinson's disease. Adv Neurol. 1987; 45: $317-21$ 